\title{
Knowledge Spillover Structure within Shanghai Districts: A Spatial Analysis of Aggregation and Correlation
}

\author{
Anyu $\mathrm{Yu}^{1, \mathrm{a}}$, Jie $\mathrm{Ma}^{2, \mathrm{~b}}$ \\ ${ }^{1,2}$ Sydney Institute of Language and Commerce, Shanghai University, Shanghai, 201800, China \\ aemail: 724786286@qq.com, 'email:1301505965@qq.com
}

Keywords: Knowledge Spillover; Spatial Autocorrelation; Gravity Model; Principle Component Analysis

\begin{abstract}
According to previous empirical researches in developing nations, study of knowledge spillover effect within urban districts is scarce. Based on the spatial autocorrelation and block analysis, this paper researched on intra-Shanghai knowledge spillover structure with enterprise-level data, by calculating the extent of knowledge aggregation and correlation with methods of local Geary's $C$ statistics and Concor algorithm. The results of aggregation analysis and correlation analysis highlight that knowledge stocks volume within different Shanghai districts are various, which indicates that knowledge spillover effects in Shanghai are unbalanced. According to unbalanced knowledge spillover effects, Shanghai could be divided into four regions. For each region, this paper finally outlines a few scenarios to enhance knowledge spillover effect.
\end{abstract}

\section{Introduction}

Knowledge spillover effect could be considered as one of the most important factors for innovation and technology updating. Relevant knowledge spillover study was proposed in 1960th, MacDougall (1960) firstly considered that Foreign Direct Investment (FDI) can break technical knowledge broadens [1]. Furthermore, the concept of "spillover" was proposed by Kokko in 1992, which means that the subsidiary of Multinational Corporation (MNC) could not acquire the whole benefit from leading the local technology improvement [2].

Spatial structure can affect knowledge spillover effect. It is discovered that knowledge spillover effect decreases with the increasing geographic distance through the research of university and high-technology industries in Austria. In addition, geographic agglomeration of companies leads to knowledge spillover which has been proved by Jaffe (1993), Audretsch and Feldman (1996) [3][4]. Therefore, knowledge agglomeration research can be recognized as an important way to study knowledge spillover extent.

The correlation of knowledge flow is also another important way to study the effect of knowledge spillover and regional innovation. Under the background of wide spread trend of globalization, international knowledge flow triggers and promotes technology innovation. Closer integration leads to more idea flows which can improve technological progress and productivity growth. Moreover, innovation externality also accelerates economic growth with technological knowledge flows [5]. Therefore, the relation of knowledge flow is also another important way to study the affect of knowledge spillover and regional innovation.

To analyze the effect of knowledge spillover, R\&D expense, patent number, labor and trade are four main indicators calculated in previous researches.

R\&D (Research and Development) expense can improve the production of a company, which is an important knowledge spillover indicator. It is discovered that stock of R\&D expense contributes knowledge spillover effect by by Coe, Helpman (1995), Basant ,Fikkert (1996) [6] [7].

Another important indicator is patent number, which is accepted by Jaffe (1993), Maursth and Verspagen (2002) and Gomes-Casseres (2006) [4][8][9]. The joint patent has been used to analyze the technological relatedness of university-industry collaborations with the data from 33 universities of 27 countries in European Union [10].

Yasuyuki Todo and Weiying Zhang (2009), Chihiro Watanabe, Bing Zhu (2001) concluded that human resource has a positive role on absorbing the technology and improving knowledge spillover 
effect [11] [12]. These researches highlight that labor of high quality can also motivate knowledge spillover effect.

It is also discovered that the international trade can accelerate the production growth and international knowledge spillover by Coe and Helpman(1995), Jaumotte (1999), Acharya and Keller(2008) [6][13] [14].

In this paper, the reason to choose knowledge spillover effect in districts of Shanghai as research object is its significant role in Chinese business and innovation field. The fastest developing regions in China are the Pearl River Delta, Yangtze River Delta and the rim area of Bohai Sea. Shanghai, as the most important Business Center in Yangtze River Delta, has successfully attracted most multinational enterprises to set headquarters here. Neighbor provinces in Yangtze River Delta especially Zhejiang and Jiangsu provinces also benefit from the knowledge spillover effect from Shanghai by regional contacts. In addition, analyzing the knowledge spillover structure of Shanghai can also predict the change of industrial structure during the process of urbanization.

However, many recent studies mainly focus on the spillover condition on the vision of country level or state level, there is still a lack of detailed analysis within districts. This paper aims to evaluate the spatial structure of agglomeration and knowledge spillover correlation within Shanghai districts and gives representative policy recommendations. With enterprise-level data, Local Geary' s C statistics is used to analyze the spatial agglomeration of knowledge stock in each district, the intensity of the correlation among different districts is calculated by using Concor algorithm.

\section{Data}

The data source of 18 Shanghai districts is mainly from Shanghai statistic yearbook 2009-2012 and Shanghai scientific statistic yearbook 2009-2012. As large-middle size companies are one of the most important knowledge spillover source acknowledged in previous researches, this paper selects 9 indicators from previous research of medium and large- size companies in 18 Shanghai districts. 18 districts in this paper are based on the division of Shanghai districts in 2010.

Table I. Indicator system

\begin{tabular}{|c|c|c|}
\hline \multirow{9}{*}{$\begin{array}{l}\text { Knowledge } \\
\text { Spillover } \\
\text { Indicator }\end{array}$} & \multirow{2}{*}{ Labor } & R\&D Staff Number; Unit: Population/ KM ${ }^{2}$ \\
\hline & & Scientific Staff Number; Unit: Population/ KMㄹㄹ \\
\hline & \multirow{4}{*}{$\begin{array}{l}\text { R\&D } \\
\text { Expense }\end{array}$} & Scientific Institute Expense; Unit: Thousand Yuan/KM ${ }^{2}$ \\
\hline & & $\begin{array}{l}\text { Inner-enterprise Expense of Scientific Project; Unit: Thousand } \\
\text { Yuan/ } \mathrm{KM}^{2}\end{array}$ \\
\hline & & $\begin{array}{l}\text { Inner-enterprise Expense of Scientific Activities; Unit: Thousand } \\
\text { Yuan/ } \mathrm{KM}^{2}\end{array}$ \\
\hline & & Inner-enterprise R\&D Expense; Unit: Thousand Yuan/ KM² \\
\hline & \multirow{2}{*}{ Trade } & Expense of Importing Technological; Unit: Thousand Yuan/ KM ${ }^{2}$ \\
\hline & & Output of New Production; Unit: Thousand Yuan/ KM ${ }^{2}$ \\
\hline & Patent & Applied Patent Number; Unit: Unit/ KM ${ }^{2}$ \\
\hline
\end{tabular}

The value of each indicator above is about the average value from 2008 to 2011 of 9 indicators.

To decrease large differences of 9 indicators' value, the average value of 9 knowledge stock indicators should be nondimensionalized by average method.

In order to reduce dimensions, this paper uses principle component analysis (short for PCA). The result of PCA indicates that the first principle component can explain $69.14 \%$ cumulative information of total information. It reflects different factors have a conflict effect. For first principle component contains largest amount of information, this paper uses the value of first principle as the aggregate indicator to explain knowledge stock for spillover.

The calculation as follow:

$Y_{i}=e_{i 1} X_{1}+e_{i 2} X_{2}+e_{i 3} X_{3}+e_{i 4} X_{4}+e_{i 5} X_{5}+\ldots . .+e_{i n} X_{n}(i=1,2 \ldots \ldots, p)$. 
$\mathrm{Yi}$ is the knowledge spillover aggregate indicator, and ein is the corresponding weight, which is the corresponding eigenvalue of first principle component, $\mathrm{Xn}$ is the value of nth variable.

Finally, Table II shows value of aggregative indicator which results from principle component analysis, the value of aggregative indicator can be thought to be the knowledge stock volume in different districts.

Table II. Knowledge stock volume in different districts

\begin{tabular}{|c|c|c|c|c|c|c|c|c|}
\hline Jinshan & $\begin{array}{c}\text { Fengxia } \\
\mathrm{n}\end{array}$ & $\begin{array}{c}\text { Songjian } \\
\mathrm{g}\end{array}$ & Xuhui & Luwan & Jingan & $\begin{array}{c}\text { Changnin } \\
\mathrm{g}\end{array}$ & $\begin{array}{c}\text { Huangp } \\
\mathrm{u}\end{array}$ & Minhang \\
\hline 47.01 & 52.76 & 106.66 & 743.03 & 438.64 & 95.88 & 120.082 & 479.275 & 437.352 \\
\hline Qingpu & Putuo & Hongkou & Zhabei & Yangpu & Pudong & Jiading & Baoshan & Chongming \\
\hline 44.530 & 203.392 & 201.6385 & 576.78 & 526.09 & $\begin{array}{c}340.7 \\
9\end{array}$ & 374.55 & 453.31 & 16.14 \\
\hline
\end{tabular}

\section{Methodology}

In this paper, knowledge spillover effect is put into two parts, one is studying the knowledge agglomeration structure, and another is the correlation of knowledge diffusion among different district. Local Geary's C statistics is used to discover hot spot districts (knowledge agglomeration districts), and to study the knowledge stock volume in neighbor districts. In addition, Concor analysis is used to analyze the knowledge diffusion relation among different regions, and classify districts of similar knowledge diffusion relation into one cluster. A district owns more knowledge stock than neighbor and has close relations with neighbor district, can be thought as a district with strong knowledge spillover effect [5].

To make the original matrix for Concor cluster, this paper uses gravity model to calculate knowledge stock attraction in different districts. The adjusted gravity model is used for calculating the intensity of technology diffusion in different cities [15]. As the data of this paper is about aggregative indicator of knowledge stock, so this paper uses basic gravity formula to calculate the correlation of technology diffusion, the formulation as follow:

$$
\mathrm{M}_{\mathrm{ij}}=\mathrm{KY}_{\mathrm{i}} \mathrm{Y}_{\mathrm{j}} / \mathrm{D}_{\mathrm{ij}}
$$

This paper defines $\mathrm{K}$ as a constant, Mij is the knowledge attraction indicator, Yi means the knowledge stock of district I, Dij means the distance between district $\mathrm{i}$ and $\mathrm{j}$. Then the data in matrix can be nondimensionalized by extremum method, the nondimensionalized value is in the range from 0 to1.

This paper uses Local Geary's C statistics to analyze the spatial agglomeration of knowledge stock in each district, then uses Concor algorithm to calculate the intensity of the correlations among different districts.

\section{Result}

The significant high/low local G statistics value means that there is a positive or negative agglomeration structure of knowledge capital in Shanghai. Moreover, knowledge spillover effect is significant in these districts.

The result of local G statistics of knowledge stock of large and medium- size companies in Shanghai shows that knowledge stock volumes in Jinshan, Fengxian, Chongming, Qingpu and Jingan District are relatively low. However, Xuhui, Luwan, Zhabei and Yangpu have higher knowledge stock volume.

Based on the result of G statistics, Z(Gi) scores of Hongkou District and New Pudong District are significant when the significant level is 0.05 and present high-value agglomeration, which means that the knowledge stock of companies around these districts are relatively higher than the 
average level of total large and medium- size companies and shows significant spatial autocorrelation. Therefore, the relatively high agglomeration of knowledge stock indicates the significant knowledge spillover possibility of large and medium- size enterprises in these districts. At the same time, districts of Jinshan and Songjiang have Z(Gi) scores much lower than -1.65 , thus presenting a significant low-value agglomeration indicating that large and medium- size enterprises in the neighbor districts have relatively low knowledge stock than the average stock and have significant spatial autocorrelation.

Furthermore, to make it more clear, a visualized figure painted by ArcGIS is shown in Figure. 1. In the figure, it is obvious that the volume of knowledge stock of large and medium- size companies in Shanghai is decreasing from the east of Shanghai to the west. Basically in Shanghai, east districts have more knowledge spillover probability than the west.

Based on data of Table II, program ucinet is used to do Concor algorithm. A suitable block should owns three or more roles, thus this paper executed twice Concor iteration to get the cluster result. Thus, through iterative computations, the result of Concor cluster highlight that 18 districts of Shanghai can be classified into 4 clusters, which is shown in Figure. 2. Cluster1 contains Hongkou ,Yangpu and Pudong districts, cluster 2 includes Huangpu, Luwan, Zhabei, Xuhui and Jingan districts, cluster 3 contains Putuo , Changning, Minhang, Songjiang, Qingpu, Fengxian and JinShan districts, cluster 4 contains Baoshan, Jiading and Chongming districts. A visualized figure painted by ArcGIS is shown in Figure. 2.

Moreover, density matrix of each cluster has also been calculated through Concor algorithm. Table III shows calculation result of the density matrix. To get the correlation of each matrix and simplify the correlations of different clusters, average density value is calculated, it is 0.102125 , nearly $10 \%$, which means that the relation of each cluster occupies only nearly $10 \%$ proportion of total possible relation, In Table III, the value higher than average value is changed to 1, other value is changed to 0 , the correlation matrix is Table IV. As can be seen from Table IV, cluster 1 and 2 has stronger effect on the knowledge diffusion extent of all the districts. Cluster 1 and 2 also has closer correlation of knowledge diffusion. There is also stronger correlation of knowledge diffusion within the districts of cluster 1 and cluster 2 .

Table III. Density matrix

\begin{tabular}{|c|c|c|c|c|}
\hline & 1 & 2 & 3 & 4 \\
\hline 1 & 0.318 & 0.211 & 0.025 & 0.042 \\
\hline 2 & 0.211 & 0.481 & 0.058 & 0.052 \\
\hline 3 & 0.025 & 0.058 & 0.01 & 0.012 \\
\hline 4 & 0.042 & 0.052 & 0.012 & 0.025 \\
\hline
\end{tabular}

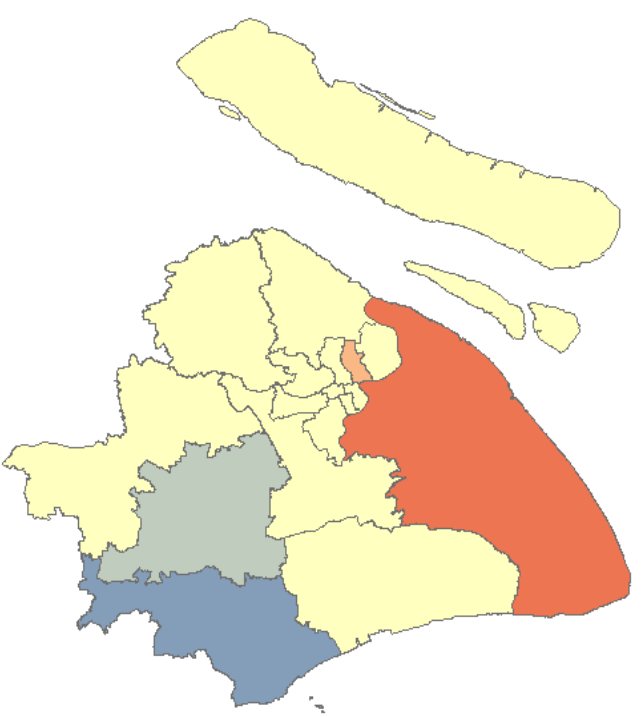

Fig.1. Local Geary’s C statistics
Table IV. Correlation matrix

\begin{tabular}{|l|l|l|l|l|}
\hline & 1 & 2 & 3 & 4 \\
\hline 1 & 1 & 1 & 0 & 0 \\
\hline 2 & 1 & 1 & 0 & 0 \\
\hline 3 & 0 & 0 & 0 & 0 \\
\hline 4 & 0 & 0 & 0 & 0 \\
\hline
\end{tabular}

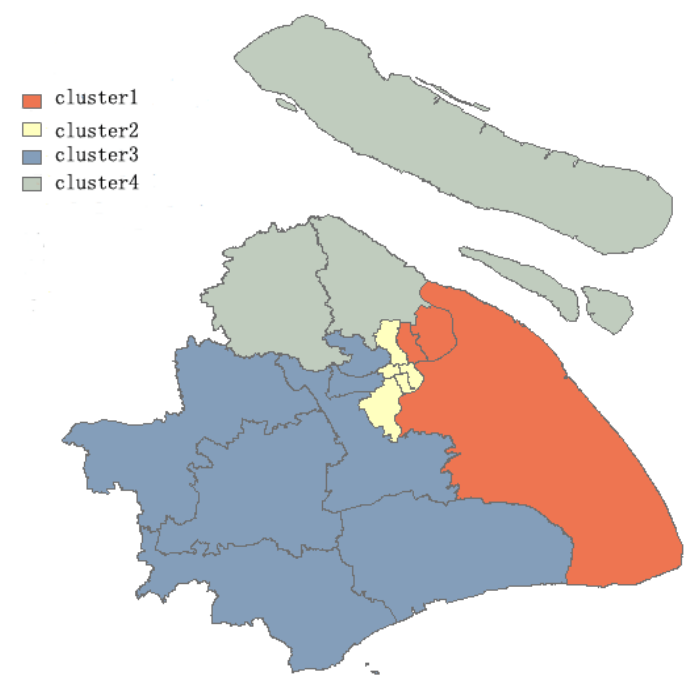

Fig.2. Result of Concor cluster 


\section{Discussion}

According to the result of local G statistics and Concor analysis of knowledge stock in districts of shanghai, districts in Shanghai can be divided into four regions, namely, eastern region, middle region, north region and western region.

First of all, in the eastern area, New Pudong District has the highest knowledge spillover stock in Shanghai, when the significant level is 0.05 . Pudong district also has strong knowledge diffusion correlation with districts in cluster 1and cluster 2. Consequently, it is concluded that New Pudong District is the most possible district of knowledge spillover in Shanghai. High agglomeration of knowledge stock expense and high aggregation of talents may lead to significant knowledge spillover in the east area. For districts in cluster1, government can take supportive policies. For example, relying on the development of Zhangjiang High-Tech Park, it is suggested to reduce relative tax and increase the income for talents. Increasing advertising and expanding social impact of Zhangjiang High-tech Park is also beneficial. In addition, it is also a great chance for New Pudong district to take advantage of businesses of ports. With more business contacts of developed countries, New Pudong district can absorb more knowledge from the world market, become peak agglomerate region of knowledge stock and increase global knowledge spillover effect in Shanghai.

Secondly, districts in the middle downtown region of Shanghai are important. Middle districts indicate an insignificant $G$ value; it means these districts do not own a higher value aggregation. However, Huangpu, Luwan, Zhabei, Xuhui, Jingan district in middle region owns strong knowledge diffusion relation with districts in cluster 1 and cluster 2. To geographic aspect, several multinational corporations located their headquarters in these districts. Most locations of universities and research laboratories are also set in this central region. As a consequence, these districts have high potential ability to absorb knowledge spillover from these organizations. Furthermore, these middle districts could be the platform for knowledge diffusion between eastern districts and those in the north-western Shanghai. To summary, there is abundant potential knowledge spillover opportunity for middle region of Shanghai. Consequently, policies should be used to encourage the number of regional innovative activities. Governments can prepare more channels for university-industry collaboration and collaboration of different districts, such as more scientific conferences and rewards for new patents. Abundant knowledge stock would attract more knowledge flows and talents, which makes a virtuous circle.

Finally, Fengxian District, Jinshan District and north-west districts of Shanghai have less knowledge stock and the $\mathrm{Z}$ ( $\mathrm{Gi}$ ) scores of those districts present low or insignificant spatial agglomeration. There is also not a strong knowledge diffusion correlation within these districts. Therefore, governments should change policies to encourage knowledge spillover of those districts by considering local advantages and disadvantages. On the one hand, the tourism in Jinshan District should be taken advantage of and be encouraged further based on the current situation. On the other hand there are several privately-run small businesses in these districts, which are always labor-intensive and short of innovation. These companies are the barriers of knowledge spillover. Therefore, additional taxes should be attached to remove them. Moreover, governments can decrease relative tax of high-tech parks and companies in these parks can increase income indirectly. It is an effective policy for governments to make it easier for multinational corporations to enter these western districts, which will increase the demand of employees and attract more talents. Finally, high-tech parks should be transformed with more effective policies of management and agglomeration of high-tech capital. Consequently, although effective policies are various, governments should attach the higher priority to these weak districts.

\section{Conclusion}

This paper analyzes the knowledge spillover structure with calculation agglomeration and correlation extent of knowledge stock in every Shanghai districts. It is underlined that the spatial structure of knowledge stock within Shanghai districts is unbalanced. In the aspect of knowledge stock volume, the trend of knowledge spillover is decreasing from the east to west in Shanghai. 
There are significant high-value agglomerations of knowledge stock and knowledge spillover correlation in Eastern districts. While the north-western districts show insufficient knowledge agglomeration and knowledge spillover correlation. Furthermore, middle downtown districts, which are insignificant in spatial agglomeration calculation of knowledge stock and have stronger knowledge spillover correlation with eastern districts, should act as the role of platform to enhance the spillover from east districts to north-western districts. Different districts and high-tech parks should be supplied corresponding privilege policies to improve knowledge spillover effect.

\section{Acknowledgment}

This research was financially supported by the Creative Activity Plan for Shanghai University Students (Grant NO. B.05-0115-11-003)

\section{References}

[1] G. D. A. Macdougall, The benefits and costs of private invest-ment from abroad: a theoretical approach[J], The Bulletin, 1960 (22)189-211.

[2] Ari Kokko, Foreign Direct Investment, Host Country Characteristics, and Spillovers, Economic Research Institute [D], Stockholm: Stockholm School of Economics, 1992.

[3] David B. Audretsch and Maryann. P. Feldman, R\&D Spillovers and the Geography of Innovation and Production [J], The American Economic Review, 1996 (86) 630-640.

[4] A. B Jaffe, Trajtenberg, Manuel, Henderson, Rebecca, Geographic Localization of Knowledge Spillovers as Evidenced by Patent Citations[J], Quarterly Journal of Economics, 1993,63, 577-598.

[5] Gene M.Grossman and Elhanan Helpman, Innovation and Growth in the Global Economy [M], 6rd ed MA: The MIT Press, 1991, 1-19.

[6] David T. Coe, Elhanan. Helpman, International R \& D spillovers[J], European Economic Review, 1995(39) 859-887.

[7] Rakesh Basant, Brian Fikkert, The Effects of R\&D, Foreign Technology Purchase, and Domestic and International Spillovers on Productivity in Indian Firms [J], The Review of Economics and Statistics, 1996 (78) 187-199.

[8] Maursth and Verspagen, Knowledge spillovers in Europe: a patent citations analysis[J], The Scandinavian Journal of Economics, 2002 (104) 531-545.

[9] Benjamin Gomes-Casseres, John Hagedoorn, Adam B. Jaffe, Do alliances promote knowledge flows? [J], Journal of Financial Economics, 2006 (80) 5-33.

[10] Antonio Messeni Petruzzelli, The impact of technological relatedness, prior ties, and geographical distance on university-industry collaborations: A joint-patent analysis[J], Technovation, 2011(31) 309-319.

[11] Yasuyuki, Weiying Zhang, Li-An Zhou, Knowledge spillovers from FDI in China: The role of educated labor in multinational enterprises[J], Journal of Asian Economics, 2009 (20) 626-639.

[12] Chihiro Watanabe, Bing Zhu, Charla Griffy- Brown, Behrooz Asgari, Global technology spillover and its impact on industry's R\&D strategies[J], Technovation, 2001 (21) 281-291.

[13] Dalia Hakura, Florence Jaumotte, The Role of Inter- and Intraindustry Trade in Technology Diffusion[Z], Washington:Working paper of International Monetary Fund,1999.

[14] Ram C. Acharya, Wolfgang Keller, Estimating the Productivity Selection and Technology Spillover Effects of Imports[Z], Massachusetts: Nber Working Paper, 2008.

[15] Fu Weizhong, Wang Can, Research on the Diffusion Intensity of Technology Innovation Based on Gravity Model and Entropy Method [J], Journal of Intelligence, 2012(31) 195-186. 